\title{
Valve-sparing reoperations for failed pulmonary autografts
}

\author{
Andrew B. Goldstone, MD, PhD, ${ }^{\mathrm{a}}$ and Y. Joseph Woo, $\mathrm{MD}^{\mathrm{b}}$
}

Aortic valve replacement is the most common valve operation performed in the United States. Options for replacement include mechanical valves, bioprosthetic valves and, less commonly, aortic valve xenografts, aortic valve homografts, and pulmonary autografts. Each substitute has associated risks and benefits. Bioprostheses are associated with a greater risk of reoperation than mechanical valves because of structural valve deterioration, but mechanical valves typically necessitate lifelong anticoagulation, which increases the risk of hemorrhage and thromboembolism. ${ }^{1}$ As a result of these associated risks, older patients often opt for bioprostheses whereas younger patients opt for mechanical prostheses. However, reports of improved durability and the initial success of transcatheter aortic valvein-valve replacement has led to implantation of surgical bioprostheses in younger and younger individuals. ${ }^{1}$

Surgeons may also replace diseased aortic valves with a living-valve substitute through the Ross procedure. ${ }^{2}$ That living substitute, the pulmonary autograft, offers excellent hemodynamics and avoids the therapeutic anticoagulation needed for mechanical prostheses. ${ }^{3}$ Drawbacks include the greater technical complexity of the Ross procedure than an isolated aortic valve replacement, trading singlevalve disease for double-valve surveillance, and more difficult reoperations if the procedure ultimately fails.

Reoperation for pulmonary autograft root dilation or autograft valve regurgitation typically consists of autograft removal and replacement with a mechanical or bioprosthetic valved-conduit. However, increasing familiarity with valve-sparing root replacement and aortic valve repair has led surgeons to preserve and/or repair the leaflets of the living autograft at the time of reoperation. ${ }^{4}$ Although data are still limited, valve-sparing reoperations for failed pulmonary autografts carry low risk and low reintervention rates in the first decade postoperatively. ${ }^{5}$

\section{RISK FOR AUTOGRAFT FAILURE}

Failure requiring reintervention after the Ross procedure typically involves the pulmonary autograft. Mechanisms for

From the ${ }^{\text {a Division }}$ of Cardiothoracic Surgery, Department of Surgery, Children's Hospital of Philadelphia, Philadelphia, Pa; and ${ }^{\mathrm{b}}$ Department of Cardiothoracic Surgery, Stanford University, Stanford, Calif.

Received for publication Jan 18, 2021; accepted for publication Jan 21, 2021; available ahead of print Feb 12, 2021

Address for reprints: Y. Joseph Woo, MD, Department of Cardiothoracic Surgery, Stanford University, Falk Building CV-235, 300 Pasteur Dr, Stanford, CA 94305-5407 (E-mail: joswoo@stanford.edu).

JTCVS Techniques 2021;10:408-12

2666-2507

Copyright (c) 2021 The Authors. Published by Elsevier Inc. on behalf of The American Association for Thoracic Surgery. This is an open access article under the CC BY-NCND license (http://creativecommons.org/licenses/by-nc-nd/4.0/).

https://doi.org/10.1016/j.xjtc.2021.01.041

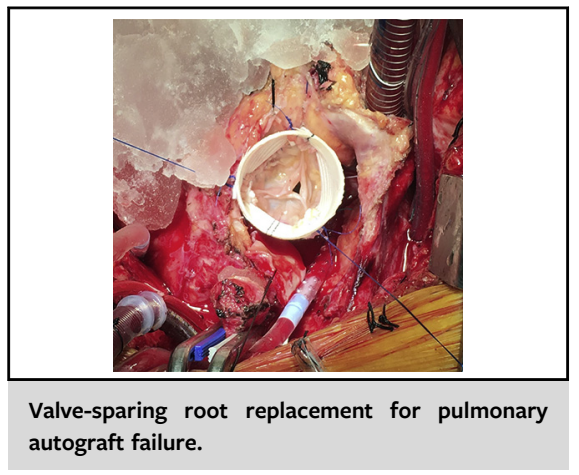

\section{CENTRAL MESSAGE \\ Increasing evidence supports the safety and efficacy of preserving the pulmonary autograft valve after Ross failure, but durability varies substantially with the mode of valve failure.}

See Commentaries on pages 413 and 415.

failure include primary leaflet failure and dilation of the annulus, sinuses of Valsalva, or sinotubular junction. ${ }^{3,6}$ Groups that report exceedingly high rates of autograft failure have also demonstrated that much of the increase in neoaortic root diameter occurred before hospital discharge. ${ }^{6}$ Therefore, Ross procedure advocates employ technical modifications to promote long-term autograft durability by preventing dilation. One such technique includes implanting the autograft deeper-in an intra-annular fashion-so that the autograft annulus is stabilized by the native aortic annulus. ${ }^{3}$ Another technique, which we prefer, includes externally supporting the autograft by reimplanting the entire pulmonic root within a Dacron graft and creating neosinuses with anticommissural plication (Figure 1, $A$ ) and then implanting into the aortic annulus (Figure 1, B). Patients at greater risk for autograft failure include those with native aortic annulus, root, or ascending aortic dilatation, and those with aortic insufficiency. ${ }^{7}$ In these patients, adjunctive measures such as native aortic annuloplasty or external reinforcement of the autograft are employed. Of paramount importance is strict systemic blood pressure control (target $<110 \mathrm{~mm} \mathrm{Hg}$ ) in the first year after surgery, which is believed to facilitate autograft adaptation to the systemic circulation. 


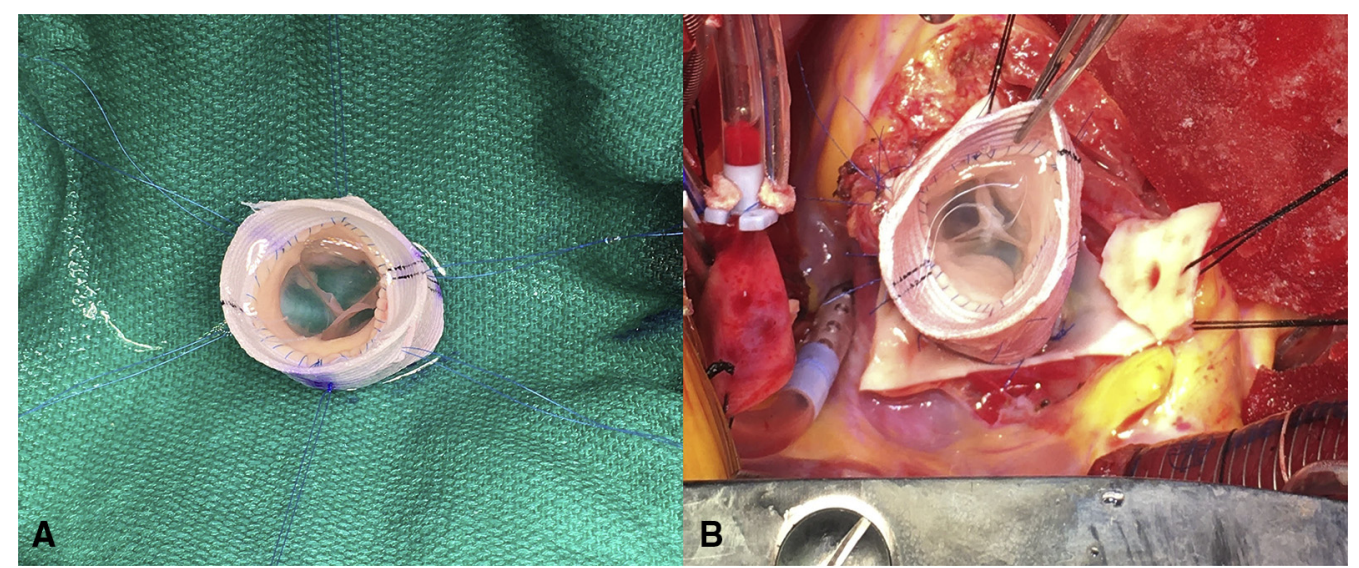

FIGURE 1. A, External support of a pulmonary autograft within a 26 straight graft. Three neosinuses are created in the graft to better accommodate the autograft sinuses by plicating the graft at 3 anticommissural points on the middle suture line. B, Intra-annular implantation of a pulmonary autograft externally supported within a 26 straight graft.

With these measures and technical considerations, a handful of groups report outstanding long-term pulmonary autograft durability. ${ }^{8-11}$ With well more than 3000 patients who underwent the Ross procedure as adults between studies, estimated 20-year incidence of autograft reintervention ranged from $11 \%$ to $25 \% .^{8-11}$ Some note that there is a slow deterioration of autograft valve function over time. ${ }^{8,12}$ The mechanism for failure-structural valve degeneration versus autograft root dilation-affects the possibility for sparing the autograft valve at the time of reintervention.

Indications for reoperation on a failed autograft mirror those for native aortic insufficiency. ${ }^{3}$ Reports of pulmonary autograft dissection are rare,${ }^{13}$ but it is reasonable to reintervene for aortic diameters $>50 \mathrm{~mm}$ in the absence of autograft insufficiency.

\section{REOPERATION FOR THE FAILED AUTOGRAFT}

Reoperation after a Ross procedure is more complex and more akin to reoperative aortic root surgery than reoperation after conventional aortic valve replacement. Complexity further increases when both the pulmonary autograft and pulmonary homograft require reintervention. A surgeon must be comfortable with a variety of aortic and pulmonary root operations if reoperating on a patient after a Ross procedure. Despite this, mortality after reoperation for Ross failure is exceedingly low and ranges from $0 \%$ to $3 \%$ across published series. ${ }^{10,11,14}$ As is true for other aortic operations, ${ }^{15,16}$ a positive volume-outcome relationship likely exists for Ross reoperations. The published series describing outcomes of reoperations after the Ross procedure are notably from expert centers. Therefore, the generalizability of their results is questionable.

The pulmonary autograft valve may be spared at the time of reoperation to preserve the living-valve substitute, which does not require anticoagulation. In experienced hands, salvage of the autograft valve approaches or exceeds $50 \%, 5,17,18$ but this depends on the mechanism of autograft failure. Autograft valve-sparing reoperations may be performed at very low risk in experienced centers. In the largest multicenter experience of valve-sparing reoperations after the Ross procedure to date, Mookhoek and colleagues 5 achieved a $1.2 \%$ operative mortality. In fact, despite longer operative times and nearly 1 in 5 patients undergoing concomitant replacement of the pulmonary outflow graft, the operative mortality achieved by these experienced surgeons falls within the range that the Society of Thoracic Surgeons risk calculator predicts for a reoperative aortic valve replacement if calculated for patients with the average characteristics of the study population. Although the low operative mortality may result from selecting healthier patients for valve-sparing procedures, it also speaks to the technical expertise of the surgeons who performed the operations in the multicenter study. Other case series affirm that autograft valve-sparing root replacements may be performed at low risk to the patient. ${ }^{19}$ However, one must take publication bias into consideration and one's own experience when considering whether these operations should be routinely performed.

\section{TECHNICAL CONSIDERATIONS}

The available operations to spare the autograft valve depend on the mechanism of autograft failure. If the primary indication for reoperation is root aneurysm (Figure 2, $A$ ), then a valve-sparing root replacement must be performed. Both root reimplantation and root remodeling techniques have been reported for failed autografts. Although the limited available data do not demonstrate a significant difference in durability between rootreimplantation and root-remodeling techniques for sparing failed autografts, ${ }^{5,19}$ we favor the reimplantation technique in all scenarios (Figure 2, $A-D$ ). ${ }^{20,21}$ 


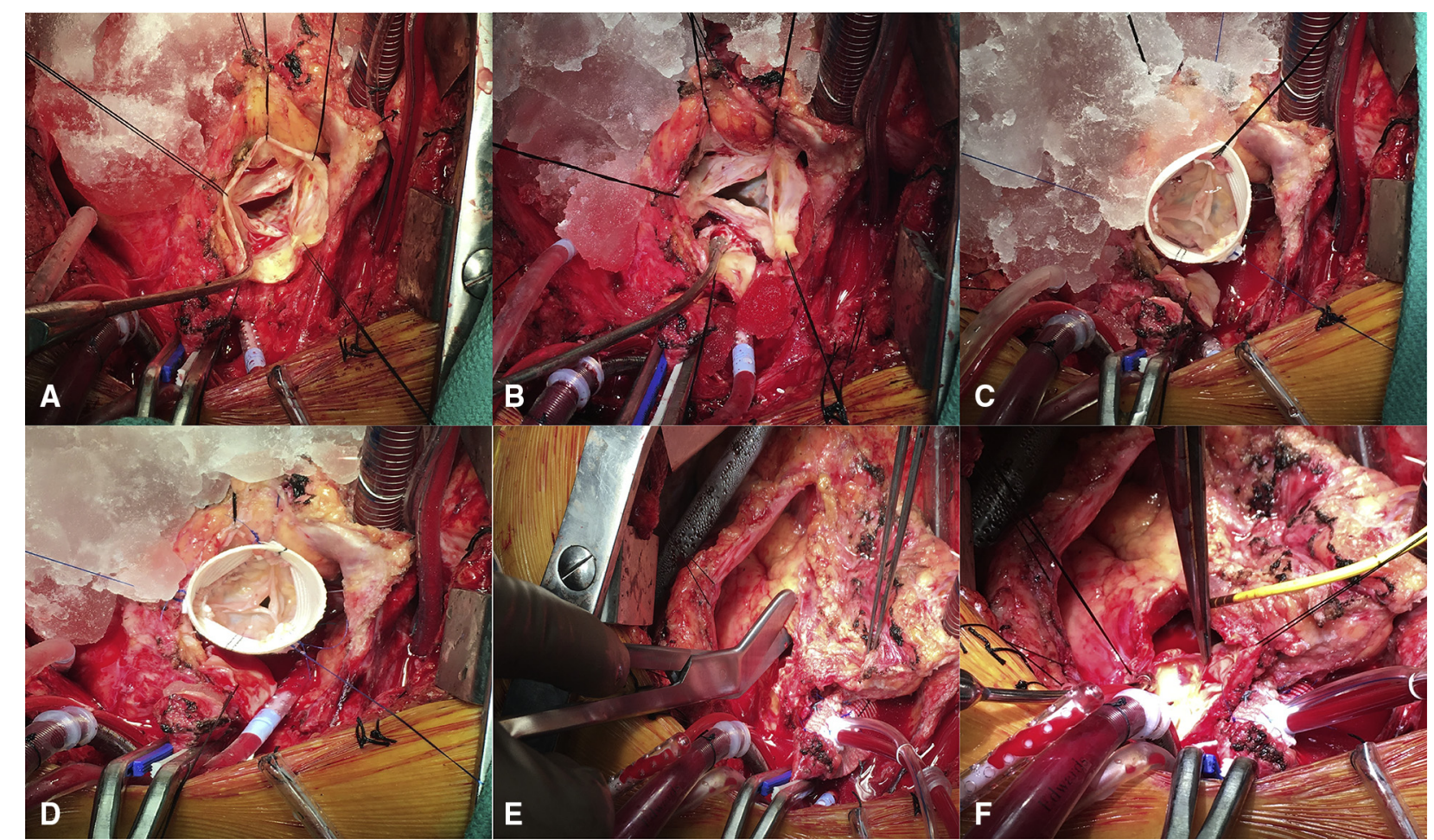

FIGURE 2. A, Pulmonary autograft aneurysm before root reconstruction. B, Aortic root dissection with preservation of the autograft valve. C, Autograft valve reimplanted into a straight graft. D, Completion of the secondary suture line. E, Opening the anterior aspect of the calcified pulmonary homograft into the right ventricular outflow tract with bandage scissors. F, View of the right ventricular outflow tract with the homograft valve leaflets excised.

The autograft root is dissected and coronary buttons are mobilized in a similar fashion to conventional reoperative root surgery, except the autograft valve is preserved (Figure $2, B$ ). It is important to free the aortic root circumferentially down to the basal ring. This may be particularly difficult if the pulmonary homograft is very adherent. If excessively adherent, one can cut a small notch into the Dacron graft to accommodate this region. We prefer to use a straight graft (Terumo Medical, Somerset, NJ) instead of a Valsalva graft (Terumo) and size the graft by adding 3 to the largest Medtronic Freestyle sizer, which passes fully through the aortic annulus. ${ }^{22}$ In most cases, a 28 graft is used, although occasionally a 30 graft is needed for larger men and a 26 graft is needed for smaller woman. Twelve subannular sutures anchor the graft in a coronet fashion. The commissures are mounted within the graft $120^{\circ}$ apart from one another (Figure 2, C). If prolapse is detected during initial valve analysis, it can be addressed by mounting the 2 commissures of the prolapsed cusp slightly higher than the commissure opposite the prolapsed cusp, thereby slightly elevating the cusp. Alternatively, these 2 commissures can be mounted slightly further apart than $120^{\circ}$, likewise slightly elevating the prolapsed cusp. The valve is reassessed after completion of the secondary suture line (Figure 2,D). Residual cusp prolapse can then be repaired with central, paracentral, or near-commissural plication, depending on the local anatomy and free margin alignment. After the left coronary button is reimplanted, the autograft valve is tested by administering cold blood down the graft. Palpating the graft will provide an understanding of the pressure the reimplanted valve is holding. We also disconnect the left ventricular vent tubing and assess for the absence of blood rising within the vent itself. Most importantly, transesophageal echocardiographic color-flow visualization of a long-axis view of the aortic valve will reveal aortic regurgitation. Difficulty with establishing a perfect view due to an empty left ventricle is a good sign that very little if any blood is regurgitating. The right coronary button is reimplanted after the valve repair is deemed satisfactory.

Note that the pulmonary homograft does not always need to be completely removed. While usually calcified, it can be opened anteriorly through the annulus and into the right ventricular outflow tract to eliminate any stenosis (Figure 2,E). The valve cusps are removed (Figure 2, F) and a new bioprosthetic valve may be sewn in a running fashion into the back wall of the homograft at any levelideally the least calcified portion-proximal to the pulmonary artery bifurcation. The remainder of the right ventricular outflow tract and pulmonary artery is reconstructed with bovine pericardium, which is also anastomosed to the anterior aspect of the bioprosthetic valve sewing ring 
to complete the valve implantation. Alternatively, the pulmonary homograft can be completely (or near completely) removed and replaced with a new pulmonary homograft. Risk for reoperation is substantially lower with receipt of a pulmonary homograft compared with a bioprosthetic valve during the index Ross procedure,${ }^{11}$ whether this relationship extends to those after valve-sparing procedures is not yet known.

When aortic insufficiency is the primary indication for reoperation, then an isolated valve repair with or without annuloplasty may be considered. Techniques for valve repair include those already described for treatment of isolated aortic insufficiency, including central leaflet plication and pericardial patch reconstruction. However, the available data on isolated autograft valve repair are sobering. Isolated autograft valve repair, isolated aortic regurgitation, and severe aortic regurgitation are the strongest risk factors for reintervention after autograft valve-sparing reoperations. ${ }^{4,5,23}$ It is unclear from the published data whether isolated autograft valve repair is typically inadequate or if the underlying disease process driving isolated aortic insufficiency begets suboptimal outcomes of valve-sparing reoperations. More than likely it is the latter; severe, isolated aortic insufficiency results from autograft cusp degeneration, which may preclude a durable repair. For that reason, significant cusp fenestration, calcification, or destruction (for example, with endocarditis) may be relative contraindications to valve-sparing reoperation. ${ }^{5,19}$ At the very least, one must have an informed discussion with the patient regarding the questionable durability of such a repair.

\section{DURABILITY AND SURVIVAL}

Long-term follow-up data after valve-sparing reoperations for failed pulmonary autografts are very limited. Most series focus on short-term outcomes, although a few report follow-up $\geq 5$ years after valve-sparing reoperations. ${ }^{5,19}$ Reinterventions after valve-sparing reoperations are not uncommon. Among the 81 patients who underwent valve-sparing reoperations in the multicenter European experience, 15 patients required surgical reintervention. ${ }^{5}$ Overall, the estimated incidence of reintervention at 8 years was $24 \%$. Reintervention was particularly high among patients who underwent isolated autograft valve repair $(\mathrm{n}=7$ of $11 ; 67 \%$ ), and much lower among patients who underwent autograft valve-sparing root replacement $(n=8$ of $70 ; 11 \%$ ). In a separate series of 27 patients who underwent autograft valve-sparing root replacement, the estimated incidence of reoperation at 5 years was $13.4 \% .{ }^{19}$ Notably, this series did not attempt to spare valves with severe prolapse or leaflet degeneration, given the high reintervention rates associated with complex leaflet repair in this setting.

The initial type of Ross procedure (complete root, supported, or subcoronary) may impact the likelihood with which the autograft valve may be spared at reoperation. ${ }^{5}$
The supported Ross is associated with a greater risk of reintervention after valve-sparing reoperation. The theory behind this association is that the native geometry of the autograft root may be distorted when incorporated within a cylindrical graft, thereby leading to premature cusp prolapse and degeneration. In contrast, complete root replacement most commonly fails because of autograft dilation, which may be more amenable to a valve-sparing reoperation.

Overall, survival after valve-sparing reoperation for Ross failure is excellent $(85 \%-90 \%$ at $8-10$ years $),{ }^{5,19}$ and supports the benefits of a durable, anticoagulation-free, living-valve substitute. These survival rates are consistent with some studies investigating survival after the initial Ross procedure, ${ }^{24}$ although they are lower than that of a randomized trial comparing the Ross procedure to aortic homograft root replacement. ${ }^{25}$

\section{PATIENT SELECTION}

Our approach to valve-sparing reoperations after Ross failure mirrors our approach to aortic valve-sparing operations in general. We do not advocate an age cutoff after which a patient is no longer a candidate. Coexistent heart disease and need for autograft leaflet repair are also not contraindications. However, it is important to counsel patients that the durability of a valve-sparing reoperation may be limited in the setting of organic disease of the autograft valve and severe aortic insufficiency, even in the most experienced of hands. Valve-sparing reoperations should generally be avoided when significant leaflet calcification and destruction are present. ${ }^{4,5,19,23}$

There is no perfect substitute for the aortic valve in the young adult. Surgeons must weigh the risks and benefits of a growing number of possible therapies in a probabilistic manner, and of course respect patient preferences and social circumstances. Selecting the Ross procedure for an index operation is a difficult decision in and of itself, and selecting to preserve the autograft valve after failure may be even more difficult. The patient who undergoes a successful, durable valve-sparing reoperation will benefit greatly from this anticoagulant-free option. In contrast, the patient who requires yet another reoperation for the autograft failing not once, but twice-has suffered.

\section{FUTURE DIRECTIONS}

A small, but growing body of literature supports the feasibility and safety of valve-sparing reoperations for patients with a failed Ross. A recent revival of interest in the Ross procedure as a treatment for aortic valve disease may enhance the role for autograft valve-sparing reoperations. As the field builds experience with valvesparing reoperations, it is essential that we understand the long-term and very long-term results of these procedures. Many patients are still young at the time of 
reoperation, so very long-term comparisons with alternative therapies are especially needed. The rapid development and release of new valve prostheses-both transcatheter and surgical-as well as novel biomaterials and surgical methods for valve reconstruction (such as the Ozaki neocuspidization procedure) may provide noninferior or superior alternatives to valve-sparing reoperations in the future. Ex vivo biomechanical studies comparing valve repair techniques may add a scientific foundation to operations. ${ }^{22}$ Extension of these studies toward understanding the performance of the pulmonary autograft after the many variations of valve-sparing reoperations is of particular interest. Ultimately, surgeons will have an ever-broadening array of therapies with which to tailor the treatment of autograft valve or root disease to each individual patient.

\section{Conflict of Interest Statement}

The authors reported no conflicts of interest.

The Journal policy requires editors and reviewers to disclose conflicts of interest and to decline handling or reviewing manuscripts for which they may have a conflict of interest. The editors and reviewers of this article have no conflicts of interest.

\section{References}

1. Goldstone AB, Chiu P, Baiocchi M, Lingala B, Patrick WL, Fischbein MP, et al. Mechanical or biologic prostheses for aortic-valve and mitral-valve replacement. N Engl J Med. 2017;377:1847-57.

2. Ross DN. Replacement of aortic and mitral valves with a pulmonary autograft. Lancet. 1967:2:956-8.

3. Mazine A, El-Hamamsy I, Verma S, Peterson MD, Bonow RO, Yacoub MH, et al. Ross procedure in adults for cardiologists and cardiac surgeons: JACC state-ofthe-art review. J Am Coll Cardiol. 2018;72:2761-77.

4. de Kerchove L, Boodhwani M, Etienne PY, Poncelet A, Glineur D, Noirhomme P, et al. Preservation of the pulmonary autograft after failure of the Ross procedure. Eur J Cardiothorac Surg. 2010;38:326-32.

5. Mookhoek A, de Kerchove L, El Khoury G, Weimar T, Luciani GB, Mazzucco A, et al. European multicenter experience with valve-sparing reoperations after the Ross procedure. J Thorac Cardiovasc Surg. 2015;150:1132-7.

6. Hokken RB, Takkenberg JJ, van Herwerden LA, Roelandt JR, Bogers AJ. Excessive pulmonary autograft dilatation causes important aortic regurgitation. Heart. 2003;89:933-4.

7. David TE, Woo A, Armstrong S, Maganti M. When is the Ross operation a good option to treat aortic valve disease? J Thorac Cardiovasc Surg. 2010; 139:68-73.

8. David TE, Ouzounian M, David CM, Lafreniere-Roula M, Manlhiot C. Late results of the Ross procedure. J Thorac Cardiovasc Surg. 2019;157:201-8.
9. Martin E, Mohammadi S, Jacques F, Kalavrouziotis D, Voisine P, Doyle D, et al. Clinical outcomes following the ross procedure in adults: a 25-year longitudinal study. J Am Coll Cardiol. 2017;70:1890-9.

10. Mastrobuoni S, de Kerchove L, Solari S, Astarci P, Poncelet A, Noirhomme P, et al. The Ross procedure in young adults: over 20 years of experience in our Institution. Eur J Cardiothorac Surg. 2016;49:507-12.

11. Sievers HH, Stierle U, Charitos EI, Takkenberg JJM, Hörer J, Lange R, et al. A multicentre evaluation of the autograft procedure for young patients undergoing aortic valve replacement: update on the German Ross Registry. Eur J Cardiothorac Surg. 2016;49:212-8.

12. Sievers HH, Stierle U, Petersen M, Klotz S, Richardt D, Diwoky M, et al. Valve performance classification in 630 subcoronary Ross patients over 22 years. J Thorac Cardiovasc Surg. 2018;156:79-86.

13. Peeters G, Arrigoni SC, Schoof P, Accord RE, Mariani MA. Acute type A dissection 18 years after a Ross operation: the old prejudice. Ann Thorac Surg. 2019; 107:e255-7.

14. Mazine A, David TE, Rao V, Hickey EJ, Christie S, Manlhiot C, et al. Long-term outcomes of the Ross procedure versus mechanical aortic valve replacement: propensity-matched cohort study. Circulation. 2016;134:576-85.

15. Hughes GC, Zhao Y, Rankin JS, Scarborough JE, O'Brien S, Bavaria JE, et al. Effects of institutional volumes on operative outcomes for aortic root replacement in North America. J Thorac Cardiovasc Surg. 2013;145:166-70.

16. Goldstone AB, Chiu P, Baiocchi M, Lingala B, Lee J, Rigdon J, et al. Interfacility transfer of Medicare beneficiaries with acute type A aortic dissection and regionalization of care in the United States. Circulation. 2019;140:1239-50.

17. Martin E, Laurin C, Jacques F, Houde C, Cote J-M, Chetaille P, et al. More than 25 years of experience with the Ross procedure in children: a single-center experience. Ann Thorac Surg. 2020;110:638-44.

18. Liebrich M, Weimar T, Tzanavaros I, Roser D, Doll KN, Hemmer WB. The David procedure for salvage of a failing autograft after the Ross operation. Ann Thorac Surg. 2014;98:2046-52.

19. Ratschiller T, Eva SD, Schimetta W, Paulus P, Müller H, Zierer A, et al. Valvesparing root replacement for freestanding pulmonary autograft aneurysm after the Ross procedure. J Thorac Cardiovasc Surg. 2018;155:2390-7.

20. Goldstone AB, Woo YJ. Pulmonary autograft leaflet repair and valve sparing root replacement to correct late failure of the ross procedure. J Card Surg. 2013;28: 496-9.

21. Goldstone AB, Jensen CW, Bilbao MS, Woo YJ. Autograft valve-sparing root replacement for late Ross failure during quadruple-valve surgery. Ann Thorac Cardiovasc Surg. 2017;23:313-5.

22. Paulsen MJ, Imbrie-Moore AM, Baiocchi M, Wang H, Hironaka CE, Lucian HJ, et al. Comprehensive ex vivo comparison of 5 clinically used conduit configurations for valve-sparing aortic root replacement using a 3-dimensional-printed heart simulator. Circulation. 2020;142:1361-73.

23. Luciani GB, Lucchese G, De Rita F, Puppini G, Faggian G, Mazzucco A. Reparative surgery of the pulmonary autograft: experience with Ross reoperations. Eur J Cardiothorac Surg. 2012;41:1309-14.

24. Bove T, Bradt N, Martens T, De Wolf D, François K, de Beco G, et al. The pulmonary autograft after the Ross operation: results of 25 year follow-up in a pediatric cohort. Ann Thorac Surg. 2021;111:159-67.

25. El-Hamamsy I, Eryigit Z, Stevens LM, Sarang Z, George R, Clark L, et al. Longterm outcomes after autograft versus homograft aortic root replacement in adults with aortic valve disease: a randomised controlled trial. Lancet. 2010;376: 524-31.

Key Words: Ross procedure, valve-sparing root replacement, aortic valve repair 